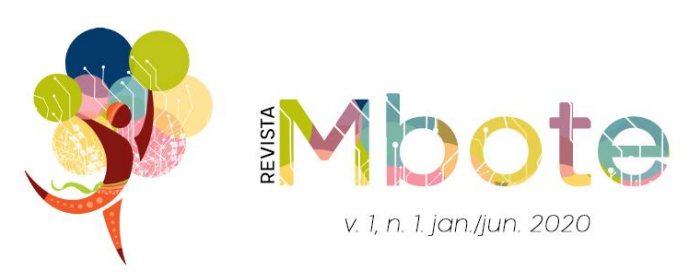

\title{
CONSTRUÇÃO DE UM CAMINHO PROFÍCUO NA ESCOLHA DE GESTORAS DE ESCOLAS PÚBLICAS
}

\author{
José Santos de JESUS ${ }^{1}$; Katia Siqueira de FREITAS ${ }^{2}$
}

\begin{abstract}
Resumo: O presente artigo resulta de um estudo sistemático da literatura sobre escolhas de gestoras escolares. Evidencia a evolução e a importância da escolha de gestoras escolar para as escolas públicas. A opção pelo gênero feminino para representar os dirigentes escolares, ocorre pelo fato de ser este o gênero predominante na ocupação dos cargos de gestão da escola básica no nordeste brasileiro. O trabalho toma por base autores que tratam do tema, como LIBÂNEO (2004), LUCK (2011), PARO (2018), FREITAS (2009), DIAS e GUEDES (2010), OLIVEIRA (2003). A pesquisa constatou que o modelo de escolha de gestoras com a participação da comunidade escolar vem se fortalecendo no Brasil e em muitos países. O texto pontua que a eleição direta para a escolha de gestoras escolares, combinando a competência técnica e experiências na docência e na gestão da escola, é um mecanismo que vem sendo cada vez mais valorizado, pelo seu potencial de contribuição para a construção da cidadania tanto no âmbito da escola, quanto no âmbito geral da sociedade. Esse modelo desconstrói as indicações políticas tradicionais de gestoras escolares a partir do entendimento de que escolhas democráticas e participativas respeitam a vontade coletiva e propiciam o envolvimento das comunidades nas tomadas de decisões.
\end{abstract}

Palavras-chave: Escolhas de gestoras. Gestão democrática e participativa. Escola Pública.

\section{BUILDING A PROFICIENT PATH IN CHOOSING PUBLIC SCHOOL MANAGERS}

Abstract: This study described the qualitative approach has as main objective to analyze the potential existing in the city of Porto Seguro, with the headquarters of Porto Seguro and the district of Arraial d'Ajuda being the place of research, using the possibilities of transforming a Consolidated Tourist Destination into a Smart Tourist Destination(STD) on the "Costa do Descobrimento". This research describes as a case of study, with methodological procedures for collecting information, the bibliographic and documentary survey, as well as a technique of systematic direct observation. The results found in relation to the potential of the City of Porto Seguro and the district of Arraial d'Ajuda for a possible transformation into a STD demonstrate that the infrastructure and equipment existing at the destination could be suitable for the STD model, however, they could also show that only the present infrastructure is not enought to meet the bases that make up the different examples of STD.

Keywords: Tourism. Management. Smart Tourist Destination. Porto Seguro.

\footnotetext{
${ }^{1}$ Doutor em Políticas Sociais e Cidadania pela Universidade Católica do Salvador (UCSAL). E-mail: jesusdabahia@gmail.com / https://orcid.org/0000-0002-3243-6656

${ }^{2}$ Doutora e Pós-doutora pela The Pennsy/vania State University, Professora pesquisadora, Universidade Católica do SalvadorUCSAL. Líder do Grupo de Pesquisa Gestão e Avaliação de Políticas e Projetos Sociais. E-mail: sfkatia@gmail.com / http://orcid.org/0000-0003-0984-814X
} 


\section{INTRODUÇÃO}

O processo de democratização na escolha de gestoras escolares é um mecanismo que tem contribuído para se repensar a gestão das escolas públicas e o papel das suas dirigentes. Na década de 1980, nos Estados Unidos (EUA), surgiu um modelo de gestão escolar, as charter schools, uma espécie de parceria público-privada que adotava a lógica da gestão privada. Essas escolas eram gratuitas para os alunos seus mantenedores eram de uma instituição de natureza privada com fins lucrativos ou não - e recebiam recursos públicos financeiros de acordo com a quantidade de alunos matriculados e com o desempenho e a qualidade da educação oferecida.

Segundo Dias e Guedes (2010), as charter schools são escolas autônomas na escolha das suas gestoras, sendo um modelo de gestão escolar que mais se adéqua às inovações no campo da gestão de escolas pois não é um modelo rígido de governança e cada escola fica livre para colocar em prática o seu modelo de gestão. A exigência maior é em torno dos resultados pedagógicos apresentados às instituições governamentais, medidos através de exames periódicos, com critérios definidos pelo governo ao fim de um determinado período.

De acordo com Dias e Guedes (2010), nos Estados Unidos, cada estado define suas normas para a seleção de gestores escolares, mas em boa parte do país cada estado exige algum tipo de certificação. A permanência no cargo depende do desempenho e da avaliação das dirigentes escolares, após ser examinada por conselhos de Educação locais, chamados de School Boards.

O quadro 1, a seguir, resume diversas formas de escolhas de gestoras em onze diferentes países:

Quadro 1 - Escolhas de gestoras escolares em 11 países

\begin{tabular}{|l|l|}
\hline País & \multicolumn{1}{|c|}{ Processos de escolha de gestoras escolares } \\
\hline \multirow{5}{*}{ Argentina } & $\begin{array}{l}\text { Bueno Aires é necessário ter no mínimo de } 5 \text { anos de carreira pública na } \\
\text { função de professora; ser certificada por curso de formação de gestão } \\
\text { escolar; análise de currículo (ter outros cursos que possam aumentar a } \\
\text { sua pontuação curricular); apresentar proposta de trabalho e ter } \\
\text { experiência de vice-gestora. No interior as exigências são menores que } \\
\text { na capital. }\end{array}$ \\
\hline
\end{tabular}




\begin{tabular}{|c|c|}
\hline Austrália & $\begin{array}{l}\text { O departamento de educação de cada estado ou território fica } \\
\text { responsável pela seleção de suas gestoras. Entretanto é o conselho da } \\
\text { escola que comanda o processo. A escolhida assina um contrato em que } \\
\text { são definidas metas para a escola - pelas quais ela será cobrada. }\end{array}$ \\
\hline Canadá & $\begin{array}{l}\text { As províncias têm autonomia para criar regras próprias de seleção. Em } \\
\text { Ontário, a mais populosa de todas as províncias, a lista de pré-requisitos } \\
\text { inclui ter especialização ou mestrado e um curso de capacitação do } \\
\text { Programa de Qualificação de gestoras, mesclando entrevista e provas. }\end{array}$ \\
\hline Chile & $\begin{array}{l}\text { Uma comissão define e anuncia o perfil da profissional desejada para } \\
\text { cada escola. As candidatas têm que fazer concurso público e apresentar } \\
\text { uma proposta de trabalho para a escola. O mandato tem duração de } \\
\text { cinco anos. }\end{array}$ \\
\hline $\begin{array}{l}\text { Coreia do } \\
\text { Sul }\end{array}$ & $\begin{array}{l}\text { Depois de fazer um curso, a candidata ao cargo de gestora deve atuar } \\
\text { como vice-gestora antes de assumir um a gestão da escola. A gestora } \\
\text { tem metas objetivas a cumprir e presta contas ao poder público. Pode } \\
\text { ficar no cargo quatro anos, com direito a um segundo mandato na escola. }\end{array}$ \\
\hline Espanha & $\begin{array}{l}\text { As aspirantes ao cargo de gestora devem ter experiência como docentes } \\
\text { por cinco anos e apresentar um projeto de gestão para a escola. Quem } \\
\text { é escolhida passa por formação inicial e só depois é nomeada. O } \\
\text { mandato é de quatro anos e pode ser renovado. }\end{array}$ \\
\hline Finlândia & $\begin{array}{l}\text { A candidata precisa comprovar experiência como professora, ter } \\
\text { especialização em gestão e passar por análise de currículo e entrevista. } \\
\text { Recebe orientação permanente do órgão público de educação local, } \\
\text { formação em serviço e pode ficar no cargo até se aposentar. }\end{array}$ \\
\hline França & $\begin{array}{l}\text { A gestora de escolas do nível equivalente aos primeiros anos do ensino } \\
\text { fundamental é escolhida por meio de entrevista realizada por um comitê } \\
\text { e precisa ter dois anos de experiência de ensino. Já para as escolas de } \\
\text { outros segmentos, as candidatas passam por um concurso de duas } \\
\text { etapas: provas e entrevistas. }\end{array}$ \\
\hline Inglaterra & $\begin{array}{l}\text { A pretendente ao cargo de gestora precisa cursar um programa de } \\
\text { formação de cerca de um ano e passar por entrevista e provas oral e } \\
\text { escrita. Os testes variam de acordo com o perfil da gestora que se } \\
\text { procura para cada instituição. A candidata pode ter que analisar um } \\
\text { projeto institucional ou participar de debate com as concorrentes. }\end{array}$ \\
\hline Portugal & $\begin{array}{l}\text { As candidatas ao cargo devem ter cursado Administração Escolar e } \\
\text { apresentar um plano de ação para determinada escola, para qual será } \\
\text { escolhida, por voto secreto, pela assembleia eleitoral, que reúne } \\
\text { representantes de toda a comunidade escolar. O mandato é de três } \\
\text { anos. }\end{array}$ \\
\hline Venezuela & $\begin{array}{l}\text { A gestora é necessariamente uma professora e é escolhida e } \\
\text { empossada por meio de indicação. }\end{array}$ \\
\hline
\end{tabular}

Fonte: Adaptado com base em Lück (2009).

As experiências e os procedimentos de escolhas das gestoras escolares, em várias partes do mundo, variam no grau de exigência da formação acadêmica, experiências profissionais e o tempo de duração do mandato.

Até a segunda metade do século passado, as professoras ou coordenadoras 
pedagógicas eram colocadas no cargo de gestora escolar, por vezes, sem nunca terem sido preparadas para o exercício da função, seja através de eleições ou simplesmente indicação. É possível vermos, no dia a dia das escolas, uma excelente professora ou coordenadora pedagógica ser promovida a gestora escolar por ser avaliada como uma ótima profissional. O problema é que muitas vezes, com essa promoção, a escola ganha uma péssima gestora e perde uma excelente professora ou coordenadora pedagógica, sendo descoberto somente algum tempo depois.

\section{ESCOLHA DE GESTORAS NO CENÁRIO BRASILEIRO}

Para Corrêa e Cardoso (2000, p. 183), a escolha da gestora escolar sempre foi um aspecto polêmico na história da administração educacional brasileira, pois esse cargo, ao longo dos anos, era tido como uma excelente forma de exercício do poder no serviço público. Desse modo, a gestora escolar ocupa um cargo estratégico de governo que pode ser usado para as manobras políticas eleitoreiras, tanto na distribuição de cargos, como na arrecadação de mais votos nos períodos de campanhas. Sendo assim, é bom que a sociedade civil não menospreze esse posto, ao acreditar que ele não faz diferença na escolha e manutenção de políticos corruptos e perversos que fazem de tudo para se manter no poder.

No Brasil as gestoras de escolas públicas eram alçadas ao cargo por políticos, prática condenada por especialistas em educação. Esses cargos eram predominantemente utilizados como moeda de troca de favores e apadrinhamentos políticos, na qual gestoras assumiam os cargos por interferência de vereadores, deputados, prefeitos e partidos políticos. A partir da Constituição de 1988 e da lei de Diretrizes e Base da Educação Nacional Lei № 9394/96- LDB9394/96-, essa forma de nomeação tem diminuído bastante, embora ainda persista em alguns estados e municípios.

A ênfase no modelo de gestão escolar democrática, observado atualmente no Brasil, é coerente com as tendências mundiais em educação e as políticas de educação nacional. O movimento em favor da reforma democrática e participativa na educação é fortemente difundido em países como Reino Unido, Nova Zelândia, Austrália, 
Estados Unidos, Canadá, Suécia e Alemanha. Essas reformas são orientadas pela preocupação com a eficácia escolar e a transparência das ações e tomadas e decisões. Existe logicamente a preocupação com a aprendizagem significativa dos alunos, de modo que estes conheçam o seu mundo, a si mesmos e tenham instrumentos adequados para enfrentar os desafios da vida. Para esses países a falta da eficácia e transparência ameaça, por certo, a legitimidade do sistema educacional e os seus resultados.

Nesse sentido, é relevante salientar a importância de elementos-chave na implementação e realização de uma gestão democrática: a construção coletiva de um projeto político pedagógico socialmente referenciado; a formação de um conselho escolar atuante e ativo, composto por representantes de segmentos que garantam a representatividade e as demandas da comunidade escolar e do entorno; e, ainda, a escolha das gestoras por meio de um processo participativo, no qual a comunidade possa expressar a sua vontade e escolha, por meio do voto direto, do grupo que liderará os projetos escolares num determinado mandato. A competência administrativa da candidata precisa ser considerada, mesmo nos sistemas que usam o sistema democrático de escolha por voto.

No entanto, tal modelo de escolha de gestoras de maneira participativa ainda não está totalmente enraizado, mas se encontra em avançado processo de construção desde os anos de 1980, sendo o município de Salvador uma das cidades pioneiras na utilização desse modelo no Brasil.

Não obstante, atualmente a literatura brasileira apresenta quatro maneiras de escolha de gestoras escolares em escolas públicas, seja na educação básica, ou mesmo na educação superior. Nesse sentido, são estabelecidas, "para fins de análise, quatro categorias de escolha de gestoras escolares: nomeação, concurso, eleição e esquemas mistos".

Paro (2018) apresenta as quatro formas mais comuns para a escolha de gestoras escolares nos sistemas públicos de ensino no Brasil são: 
a) Indicação política: Neste modelo, a figura do representante político, seja ocupante de cargo legislativo ou executivo, nos âmbitos municipal, estadual ou federal, escolhe e indica uma pessoa da sua confiança para que ocupe o cargo de direção de uma determinada escola ou universidade pública, deixando este comprometido com quem o indicou e, desse modo, submetido às suas ordens.

Do mesmo modo, essa forma de escolha não garante a qualidade técnica do profissional designado à realização de um trabalho tão importante. Esses cargos, em geral, são comissionados e frequentemente denominados como "cargos de confiança" de quem os indicou.

A livre indicação das gestoras de escola pelos políticos é uma prática extremamente complexa e marcante na educação brasileira, pois encontra-se profundamente arraigada nos vícios da política brasileira, notadamente marcada pelas relações de servilidade e de dependência política entre os envolvidos no processo. Sendo assim, esta forma de indicação não interessa à comunidade escolar, mas sim à classe política local, que usa desse cargo de confiança para controlar e transformar as pessoas em votos e benesses oferecidas aos apaniguados da classe política.

Dados do Ministério da Educação (MEC) relativos às respostas de 55 mil gestoras a um questionário aplicado em 2015 e publicados no Jornal Folha de São Paulo de 30 de setembro de 2017 indicam que, no Brasil, mais de $45 \%$ das gestoras escolares ainda eram escolhidas pelo processo de indicação política.

b) Concurso público: $O$ concurso público, a princípio, parece bastante positivo, no entanto, também apresenta um elemento obstaculizador à realização da gestão democrática, pois, nesse caso, mesmo com a garantia da aferição da qualidade técnica dos profissionais, se trata de um processo de escolha unilateral, já que a comunidade não participa, pois, o princípio da meritocracia garante aos candidatos a livre escolha, pela classificação, do local de trabalho. 
Ou seja, a gestora escolhe a escola, mas nem a escola nem a comunidade podem escolher a gestora.

O profissional que a escolhe, muitas vezes o faz se utilizando de critérios que nem sempre são positivos para elas, por não estarem agregados à sua identificação e comprometimento com a unidade a que vai servir, mas, sobretudo, à sua vida ou a aspectos pessoais, a exemplo da distância da casa ou do porte da unidade escolar.

Isso significa que o concurso acaba sendo democrático para o candidato, que, se aprovado, pode escolher a escola onde irá atuar, mas pode ser antidemocrático em relação à vontade da comunidade escolar, que precisa a aceitar a escolha do primeiro. Se assim acontece, a gestora pode acabar não tendo grandes compromissos com os objetivos educacionais articulados com os interesses dos usuários, o que gera, muitas vezes, a negligência em relação às formas democráticas de gestão, ainda que isso não possa ser considerado como regra.

c) Eleição com ampla participação da comunidade escolar: (pais, alunos, professores e funcionários da escola) por voto direto, é a mais defendida por especialistas da área educacional e a que mais se aproxima dos anseios democráticos, como requer a Constituição Federal.

A eleição de gestora pode ser um primeiro passo para a gestão democrática, porém, como todo processo de mudança, carrega desafios a serem superados da prática. $\mathrm{O}$ autor ressalta a importância da garantia, nesse modelo, da existência de um mandato com um caráter provisório, por tempo determinado, para que o gestor não se sinta seguro no cargo, a ponto de cometer abusos como centralização e autoritarismo.

Oliveira (2003) e Libâneo (2004) alertam algumas gestões consideradas democráticas e participativas, em verdade, não o são. Ainda que contemplem a presença da comunidade nos processos do desenvolvimento escolar, nos Conselhos de Escola ou nos Colegiados, nem sempre, efetivamente, incorporam nas decisões tomadas os interesses dos representados. Para eles, existem muitas formas de participações e 
experiências de gestão democrática, desde a constituição de conselhos, eleições para a escolha de gestoras escolares e outras formas de organização que permitem a participação dos diversos segmentos da comunidade escolar.

Em síntese, nesse modelo, a gestora eleita se voltará para as necessidades da comunidade que o escolheu, submetendo assim o seu mandato aos interesses, à manifestação e à vontade da comunidade escolar, seja através do voto direto ou do voto representativo, por meio de conselhos e colegiados, favorecendo a discussão democrática das questões da escola e a liberdade de expressão. Os conselhos e colegiados escolares pode ser a expressão da participação da comunidade se efetivamente representarem a vontade dos seus representados e não se acovardarem frente aos embates.

A maior vantagem do modelo de eleição é a possível rotatividade de profissionais frente à direção da escola, permitindo, assim, uma alternância no poder, o que colabora para a garantia da democracia e a ocorrência de menor autoritarismo no processo, minorando o prejuízo para a livre participação nas decisões mais importantes tomadas para a escola e permitindo, enfim, uma caminhada na direção de uma gestão democrática da escola pública.

d) Mista: é a forma de escolha de gestoras escolares com a maior incidência no Brasil. Nela existe a combinação do concurso público (profissional de carreira) e a formação profissional com a escolha por eleições diretas. Esta é a forma que mais se aproxima do ideal defendido, já que a aferição da qualidade técnica do profissional, por meio do concurso público e a realização das eleições diretas garantem a combinação entre a qualificação acadêmica para o cargo e a manifestação da vontade da comunidade escolar no processo de escolha das gestoras da escola.

Os procedimentos de escolhas das gestoras escolares já demonstram um grau de exigência e importância nesse processo em diversos países, inclusive no Brasil. Alguns especialistas defendem que pôr à frente das escolas boas gestoras é um bom 
começo para a melhoria dos índices de qualidade da educação. Para Freitas (2006), o processo educacional começa a partir da escolha da gestora escolar, que segundo a autora, é a figura principal dentro da escola, além de ser também o principal elo entre a escola, o órgão central, a comunidade escolar e do entorno. Ademais, o despreparo ou o bom preparo de uma gestora escolar afeta diretamente a docência e a aprendizagem dos alunos, já que se torna impossível melhorar a qualidade do ensino sem a atuação de um bom líder e bons professores.

Como foi sinalizado anteriormente, existem quatro formas predominantes no país para ocupar esse posto: indicação política, concurso público, voto direto da comunidade escolar e mista. Sobre o voto direto, que ocorre mediante eleições para o provimento do cargo de gestora escolar, pontuamos que, embora as eleições se apresentem como um legítimo canal na luta pela democratização da escola e das relações sociais mais amplas, e não o único, é necessário não perder de vista as limitações do sistema representativo numa sociedade de classes, assentada em interesses antagônicos e irreconciliáveis.

No Estado do Paraná, primeiro Estado Brasileiro a implantar as eleições para a escolha de gestoras escolares, a Lei № 18.590, de 13 de outubro de 2015, define critérios de escolha, mediante consulta à Comunidade Escolar, para designação de gestoras e gestoras auxiliares da Rede Estadual de Educação Básica do Paraná, na qual estabelece $o$ artigo primeiro:

Art. 1ํ. A designação de Diretores e Diretores Auxiliares da Rede Estadual de Educação Básica do Paraná é competência do Poder Executivo, a qual fica delegada, nos termos desta lei, à Comunidade Escolar, mediante consulta a ser realizada simultaneamente em todos os Estabelecimentos de Ensino. (PARANÁ, 2015).

Após eleitas, as gestoras escolares passam por um curso de gestão escolar, volvido à formação continuada, ao mesmo tempo que exerce as suas atividades. Depois de dois anos, o trabalho delas é avaliado pelos membros do Conselho Escolar. Se a avaliação chegar a conclusão de que as ações do mandato estão caminhando de acordo com o que foi planejado, de acordo com as leis, incluindo a parte financeira, o 
mandato terá continuidade. Se problemas forem verificados, o Conselho pode decidir por adotar medidas de ajustes, podendo incluir acompanhamento do órgão central ou pode recomendar uma nova eleição para a escolha de novas gestoras.

Atualmente, em boa parte dos municípios brasileiros, as gestoras escolares são escolhidas por meio da participação da comunidade escolar, superando o modelo de indicação política, que ajuda a manter o ocupante do cargo de gestora por vários mandatos, de acordo com os vínculos que constituem com a gestão política da cidade e seus políticos.

A Fundação Victor Civita (FVC), em 2016, publicou uma pesquisa encomendada ao Centro de Desenvolvimento Humano Aplicado (CEDHAP), que traçou um cenário das práticas de escolha e capacitação de gestoras existentes no Brasil a partir de informações fornecidas pelas próprias redes de ensino. A pesquisa constatou que a eleição é a principal forma de acesso ao cargo, sendo mencionada por $67 \%$ das Secretarias de Educação; a indicação aparece em segundo lugar (42\%). Metade das redes de ensino pesquisada combina duas ou mais modalidades. Um terço delas informou utilizar critérios técnicos para a seleção de gestoras, como provas, exames de certificação, entrevistas e concursos (FUNDAÇÃO VITOR CIVITA, 2010 apud INSTITUTO UNIBANCO, 2016).

Um estudo da Fundação Itaú Social, de 2015, se refere ao processo de seleção de gestoras nas escolas públicas brasileiras, concluindo que "processos seletivos mais transparentes (vinculados a exame de seleção e/ou eleição) em geral escolhem gestoras que permanecem muito mais tempo nas escolas e que apresentam características de liderança positivas (como identificado pelo incentivo à formação continuada dos professores)", o que não se verifica no caso das gestoras indicadas.

A figura 1 mostra o panorama de incidências de participação em eleições para escolhas de gestoras para atuarem em escolas públicas no Brasil: 
Figura 1 - Modalidades de seleção para gestoras de escolas públicas

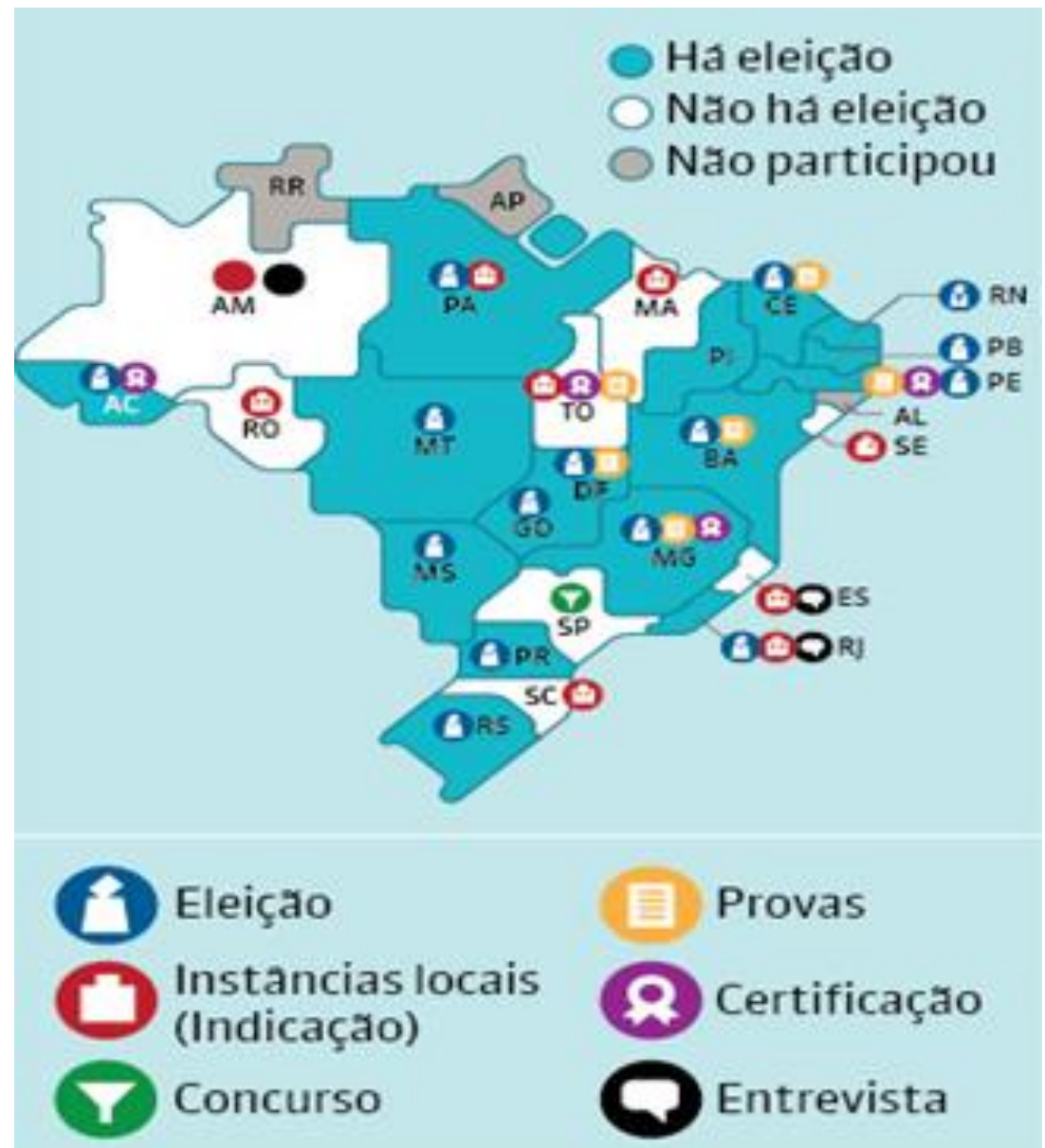

Fonte: Fundação Vitor Civita (2010, p. 2 apud INSTITUTO UNIBANCO, 2016).

O atual Plano Nacional de Educação (PNE), Lei n 13.005/2014, reforça a Lei de Diretrizes e Bases da Educação Nacional (LDB 9.394 de 1996), trazendo na meta 19: a recomendação para que sejam garantidas ".. as condições, no prazo de 2 anos, para a efetivação da gestão democrática da Educação, associada a critérios técnicos de mérito e desempenho e à consulta pública à comunidade escolar, no âmbito das políticas públicas, prevendo recursos e apoio técnico da União para tanto" (BRASIL, 2014)

Sendo assim, o PNE sugere as estratégias para o alcance da referida meta, entre eles estão os estímulos à formação de conselheiros do FUNDEB; a criação de Fóruns Permanentes de Educação nos entes federados, a necessidade de criação de grêmios estudantis e associações de pais, além da criação e fortalecimento dos conselhos municipais. 
Considerando a situação do Rio Grande do Sul, em grande parte dos sistemas de ensino estaduais, o cargo de gestão de estabelecimentos escolares, departamentos e outras unidades administrativas da educação pública permanece como "cargo de confiança", sendo ocupado por pessoas indicadas pela hierarquia da gestão da educação, com critérios independentes da formação específica e da admissão por concurso.

Na Bahia, a Secretaria Estadual de Educação (SEC) divulgou o Decreto do Estado da Bahia no 13.202/2011, que instituiu pela primeira vez as eleições diretas para a escolha de gestoras das escolas de Educação Básica do Estado da Bahia. Posteriormente, o Decreto, № 16.385, de 26 de outubro de 2015, publicado no Diário Oficial do Estado da Bahia (DOE), trouxe critérios definidos para eleição de gestoras e vice-gestoras das escolas da rede estadual de ensino, assegurando que alunos a partir de 12 anos, com frequência regular, pais e responsáveis por estudantes e servidores públicos, municipais, estaduais e federais, lotados na unidade escolar, teriam direito ao voto.

Para concorrer aos cargos, é necessário ser servidor de carreira do Magistério Público Estadual, no cargo de professor ou coordenador pedagógico; ter formação superior com licenciatura plena; ter sido aprovado na avaliação de conhecimento em gestão escolar, conhecido como "Certificação"; e ter experiência docente de, no mínimo, dois anos, em escolas da rede pública ou privada. As gestoras e vice-gestoras eleitas tiveram mandato de quatro anos, podendo ser reeleitas em mais um processo seletivo.

Em seguida, a Resolução n 26/2016, do Conselho Estadual de Educação (CEE) da Bahia, define normas para o funcionamento das instituições de ensino da Educação Básica. O capítulo III, Art. 12 da Referida Resolução, diz que as condições de funcionamento da instituições de Ensino da Educação Básica, deve ser gerida por uma gestora com licenciatura, sendo possível a formação em ensino médio, na modalidade magistério, para atuar em instituição exclusivamente com oferta de Educação Infantil e Ensino Fundamental nos anos iniciais. 
Na cidade do Salvador - Bahia, a forma de escolha pode ser denominada mista, já que, nela, os aspirantes aos cargos de gestoras escolares devem pertencer ao quadro efetivo do magistério municipal, realizar uma formação com caráter eliminatório, apresentar um plano de ação para a escola que pretende gerir e, após tais etapas, montar uma chapa e apresentar-se à comunidade escolar para que esta se manifeste no tocante à legitimação da chapa que deve assumir o mandato, que tem duração de 03 (três) anos e podendo ser renovado, somente, por mais uma vez.

Segundo a legislação Decreto № 30.118, de 29 de setembro de 2018, publicado no Diário Oficial do Município de Salvador, para ser gestora escolar é necessário atender certos requisitos: ser uma professora ou coordenadora pedagógica concursada; ter passado pela experiência de pelo menos três anos de serviço; ter nível superior; participar do curso de gestão escolar oferecido pela Secretaria de Educação, devendo obrigatoriamente ter uma frequência mínima de $75 \%$; passar também por uma avaliação escrita, obtendo a aprovação com nota 5,0; e, posteriormente, passar por um processo de eleição ${ }^{1}$ direta pela comunidade escolar, através do voto direto assegurado na Lei Municipal oํ 036, de 2004 (SALVADOR, 2004).

Diversos municípios baianos já experimentam essa forma de escolha das gestoras com a participação da comunidade, a exemplo dos municípios de Alagoinhas, Vitória da Conquista, Itacaré, Lauro de Freitas, Feira de Santana, Barreiras, Porto Seguro, dentre outros.

O fato é que cada rede pública vem estabelecendo critérios próprios para que o gestor escolar possa assumir o cargo. Contudo, depende da política de adotada por cada secretaria de educação, que pode acontecer desde indicações pessoais e políticopartidárias, passando pelo concurso público ou até eleições. Em contrapartida,

\footnotetext{
${ }^{1}$ Existe atualmente um grande debate, entre representantes do Órgão Central e representantes dos trabalhadores em educação, quanto ao termo a ser utilizado nas próximas escolhas dos novos gestores, se "eleição" ou "consulta".
} 
algumas secretarias de educação exigem como requisitos certo tempo de atuação em sala de aula para que os profissionais possam assumir a função de gestora escolar.

Segundo Lück (2011), existe uma tendência mundial que aponta para a profissionalização da gestora, tendo em vista que as exigências técnicas e de formação estão cada vez mais presentes nos processos de escolhas dos dirigentes educacionais, como uma maneira de garantir os mais bem qualificados para 0 exercício do cargo. Há também uma disposição crescente em entender que a gestora tem como papel basilar ser líder da comunidade, como gestora pública da educação e não como um simples emissário ou preposta do governo.

\section{CONSIDERAÇÕES}

Atualmente, gerir não é tarefa simples, é uma atividade multifacetada. A gestora da escola publica enfrenta muitas situações adversas e também situação contraditória, quer tenha sido conduzida ao cargo por eleição ou não. Na função de responsável pela escola e de preposta do Estado ou do município, no que se refere à execução das leis e da ordem na escola, adiciona-se o seu necessário papel de líder, legitimado ou não pelo voto da sua comunidade, o que requer muita atenção aos interesses das comunidades escolar e local..

Nessa perspectiva, podemos afirmar que, quando a democracia e a participação são garantidas, há maior probabilidade dos interesses das comunidades escolar e local serem respeitados. A eleição direta livre, se associada a alguns critérios, como formação técnica, conhecimento dos direitos humanos, respeito ao próximo, empatia, contribuem que a gestão das escolares seja transparente e eficiente.

O profissional da educação deve implementar formas de gestão democrática, entendida como superação do conhecimento de administração enquanto técnica e apreender o significado social das relações de poder que se estabelecem no cotidiano da escola, nas relações entre os profissionais, entre estes e os alunos, assim como na concepção e elaboração dos conteúdos curriculares. 
Todos os que estão envolvidos no cotidiano escolar precisam participar da gestão da escola. Isto requer o envolvimento de pais ou responsáveis, alunas, professoras, gestoras, coordenadoras pedagógicas, secretárias escolares, secretários de educação e até prefeitos e governadores, além das pessoas que participam de projetos na escola, e toda a comunidade ao entorno dela. Nesse sentido, a tendência é a gestão democrática motivar a todos os envolvidos no processo educacional a pensarem juntos melhorando a qualidade da educação.

O modelo de escolha e atuação do diretor escolar pode contribuir para a superação de conflitos, para a melhoria do trabalho, para as relações intra e extra-escolares e para a qualidade do ensino pública, propiciando mudanças profundas na própria estrutura da escola e nas relações de poder que nela se desenvolvem. Entretanto, o processo de eleição de gestoras escolares é apenas um dos elementos da gestão democrática do ensino público. O comprometimento com o sucesso da instituição e dos seus educandos é o centro do trabalho de getão.

A história da gestão escolar no Brasil e em boa parte do mundo vem se desenhando por mudanças significativas ao longo dos anos. Mudanças na seleção da gestora da escola pública refletem mudanças nas políticas, e na sociedade. A participação do cidadão em todos os âmbitos sociais é reflexo do fortalecimento da democracia.

O texto discutiu vários caminhos para que a escolha de gestores de escolas públicas, como eleição direta para a escolha de gestoras, combinada com a competência técnica e experiências na docência e na gestão da escola. Esse, sem sombra de dúvidas, tem se tornado o caminho cada vez mais utilizado como meio de acesso a gestão da escola.

\section{REFERÊNCIAS}

BAHIA. Portaria no 13.202, de 19 de agosto de 2011. Regulamenta o artigo 18 da Lei no 8.261 , de 29 de maio de 2002, dispondo sobre os critérios e procedimentos do processo seletivo interno a ser realizado pela unidade escolar, requisito para 0 preenchimento dos cargos de Diretor e Vice-diretor das Unidades Escolares do Estado da Bahia, e dá outras providências. Salvador, 2011. Disponível em: 
https://governoba.jusbrasil.com.br/legislacao/1028911/decreto-13202-11. Acesso em: 11 jul. 2019.

BAHIA. Decreto $n^{\circ}$ 16.385, de 26 de outubro de 2015. Dispõe sobre os critérios e procedimentos do processo seletivo interno a ser realizado pela unidade escolar, requisitos para o preenchimento dos cargos de Diretor e Vice-Diretor das unidades escolares estaduais, conforme disposto no art. 18 da Lei no 8.261, de 29 de maio de 2002 - Estatuto do Magistério, e dá outras providências. Salvador, 2015. Disponível em:

http://escolas.educacao.ba.gov.br/system/files/private/midiateca/documentos/2015/d ecreto-no-16385-de-26-de-outubro-de-2015.pdf. Acesso em: 11 jul. 2019.

BAHIA. Conselho Estadual de Educação. Resolução CEE no 26, de 15 de março de 2016. Fixa normas para o funcionamento das instituições de ensino da Educação Básica integrantes do Sistema Estadual de Ensino da Bahia. Salvador, 2016. Disponível em: http://escolas.educacao.ba.gov.br/system/files/private/midiateca/documentos/2016/re s-26-com-82.doc. Acesso em: 11 set. 2018.

BRASIL. Constituição (1988). Constituição da República Federativa do Brasil. Brasília, DF: Senado Federal: Centro Gráfico, 1988.

BRASIL. Presidência da República. Casa Civil. Lei no 9.394, de 20 de dezembro de 1996. Lei de Diretrizes e Bases da Educação Nacional. Estabelece as diretrizes e bases da educação nacional. Brasília, DF, 1996. Disponível em: http://www.planalto.gov.br/ccivil_03/leis//9394.htm. Acesso em: 16 abr. 2017.

BRASIL. Presidência da República. Casa Civil. Lei 13.005, de 25 de junho de 2014. Aprova o Plano Nacional de Educação - PNE e dá outras providências. Brasília, DF, 2014. Disponível em: https://presrepublica.jusbrasil.com.br/legislacao/125099097/lei13005-14\#art-1. Acesso em: 08 jul. 2019.

CORRÊA, J. J.; CARDOSO, A. C. F. As eleições para diretores enquanto instrumento de democratização da gestão escolar: uma análise da experiência implantada na rede municipal de ensino de Ponta Grossa. Ensaio, Rio de Janeiro, v. 8, n. 27, abr./jun. 2000.

DIAS, Maria Carolina Nogueira; GUEDES, Patrícia Mota. O modelo de escola charter: a experiência de Pernambuco. São Paulo: Instituto Fernand Braudel de Economia Mundial : Fundação Itaú Social, 2010.

FREITAS, K. S. Gestão da Educação: a formação em serviço como estratégia de melhoria da qualidade do desempenho escolar. Salvador: EDUFBA, 2009.

FREITAS, K. S.; SOUSA, J. V. Progestão: como articular a gestão pedagógica da escola com as políticas públicas da educação para a melhoria do desempenho escolar? Módulo X. Brasília, DF: Conselho Nacional de Secretários de Educação, 2009. 
FUNDAÇÃO ITAÚ SOCIAL. Relatório anual 2015. Disponível em: https://www.itausocial.org.br/wp-content/uploads/2018/05/02-relatorio-anualfundacao-itau-social-2015_1510160115.pdf. Acesso em: 11 jul. 2019.

INSTITUTO UNIBANCO. Escolha de diretores escolares deve contemplar princípio da gestão democrática. São Paulo, 2016. Disponível em: https://www.institutounibanco.org.br/aprendizagem-em-foco/12/. Acesso em: 10 jul. 2019.

LIBÂNEO, J. C. Organização e gestão da escola: teoria e prática. 4. ed. Goiânia: Alternativa, 2004.

LÜCK, H. Dimensões de gestão escolar e suas competências. Curitiba: Positivo, 2009.

OLIVEIRA, E. C. Gestão de recursos humanos a escola. Fortaleza: Editora da UECE, 2003.

PARANÁ. Lei no 18.590, de 13 de outubro de 2015. Dispõe sobre a definição de critérios de escolha mediante a consulta à Comunidade Escolar para designação de Diretores. Curitiba, $2015 . \quad$ Disponível em: http://www.legislacao.pr.gov.br/legislacao/pesquisarAto.do?action=exibir\&codAto=14 7837\&codltemAto=904159. Acesso em: jul. 2019.

PARO, V. H. Administração escolar: introdução crítica. 16. ed. São Paulo: Cortez, 2018.

SALVADOR. Câmara Municipal. Lei complementar no 36, de 30 de abril de 2004. Dispõe sobre o Estatuto dos Servidores do Magistério Público do Município do Salvador. Salvador, $2004 . \quad$ Disponível em: https://leismunicipais.com.br/a/ba/s/salvador/lei-complementar/2004/3/36/leicomplementar-n-36-2004-dispoe-sobre-o-estatuto-dos-servidores-do-magisteriopublico-do-municipio-do-salvador. Acesso em: 08 maio 2018. 